\title{
ОСОБЕННОСТИ РАЗВИТИЯ ИМПУЛЬСНЫХ РАЗРЯДОВ в СильНОПРОводящих жидкОСтях
}

Как показали наши исследования, для проведения химических реакций необходимо организовать импульсный разряд в жидкостях, обладающих резко различной проводимостью, в диапазоне от $10^{-5}$ до $0,1 \mathrm{oM}^{-1} \cdot \mathrm{cM}^{-1}\left[{ }^{1-3}\right]$.

При изучении пробоя жидкостей с различной проводимостью предел проводимости изучаемых сред составлял в основном от $10^{-14}$ до $10^{-4}$ oм$^{-1} \cdot \mathrm{CM}^{-1}\left[{ }^{4}, 5\right]$. Разряд в жидкостях с более сильной проводимостью изучался небольшим чнслом исследователей $\left[{ }^{6}, 7\right]$.

Установлено, что с повышением электропроводности раствора снижаются значения критических напряжений, увеличивается число и яркость ветвей и уменьшается скорость их развития. Г. А. Остроумов с сотрудниками $\left[{ }^{7,8}\right]$ обнаружили ряд особенностей развития разряда в электролитах и показали, что в жидкостях с проводимостью свыше $0,1 o^{-1} \cdot c M^{-1}$ пробой отсутствует даже при малых разрядных промежутках $(0,25$ м.м. Они показали также, что род ионов имеет второстепенное значение в процессе пробоя. Нєобходимо отметить, что в указанных работах энергия, вводимая в разрядный промежуток, составляла 20 дж. Из анализа литературных данньіх следует, что в настояшее время отсутствуют экспериментально обоснованные представления о развитии импульсного разряда в жидких средах с разной проводимостью на больших промежутках при резко неоднородном поле.

В настоящем сообщении приведены некоторые закономерности развития разряда в электролитах (щелочных, нейтральных и кислых средах) в зависимости от параметров разрядного контура, электрофизических свойств среды, полярности и геометрии разрядного промежутка.

\section{Методика}

Исследование разрядов проводилось на установке, принципиальнал схема которой изображена на рис. 1. Импульсная высоковольтная установка позволила изменять параметры разряда в широком диапазоне: напряжение с крутым фронтом $\tau=10^{-7}$ секдо $50 \kappa 8$, емкостью $C$ от 0,044 до 3 мк $\phi$, с максимальной индуктивностью контура $L$ 6,3 мкан [ $\left.{ }^{1}\right]$.

Сигналы тока и напряжения подавались на пластины осциллографа ОК-17. Сигналы тока снимались с безындукционных трубчатых шунтов, сигналы напряжения на разрядном промежутке подавались на осциллограф через емкостный или омический делитель. Параллельно процесс развития разрядов исследовался фотографически.

Производилось интегральное (статическое) фотографирование процесса фотоаппаратом «Зенит» с применением различных светофильтров и скоростное фотографирование разряда с помощью фоторегистрирующей установки СФР-2М в режиме лупы времени; скорость съемки была $1,5 \cdot 10^{6}$ кадров/сек. Разряд инициировался высоковольтным им- 


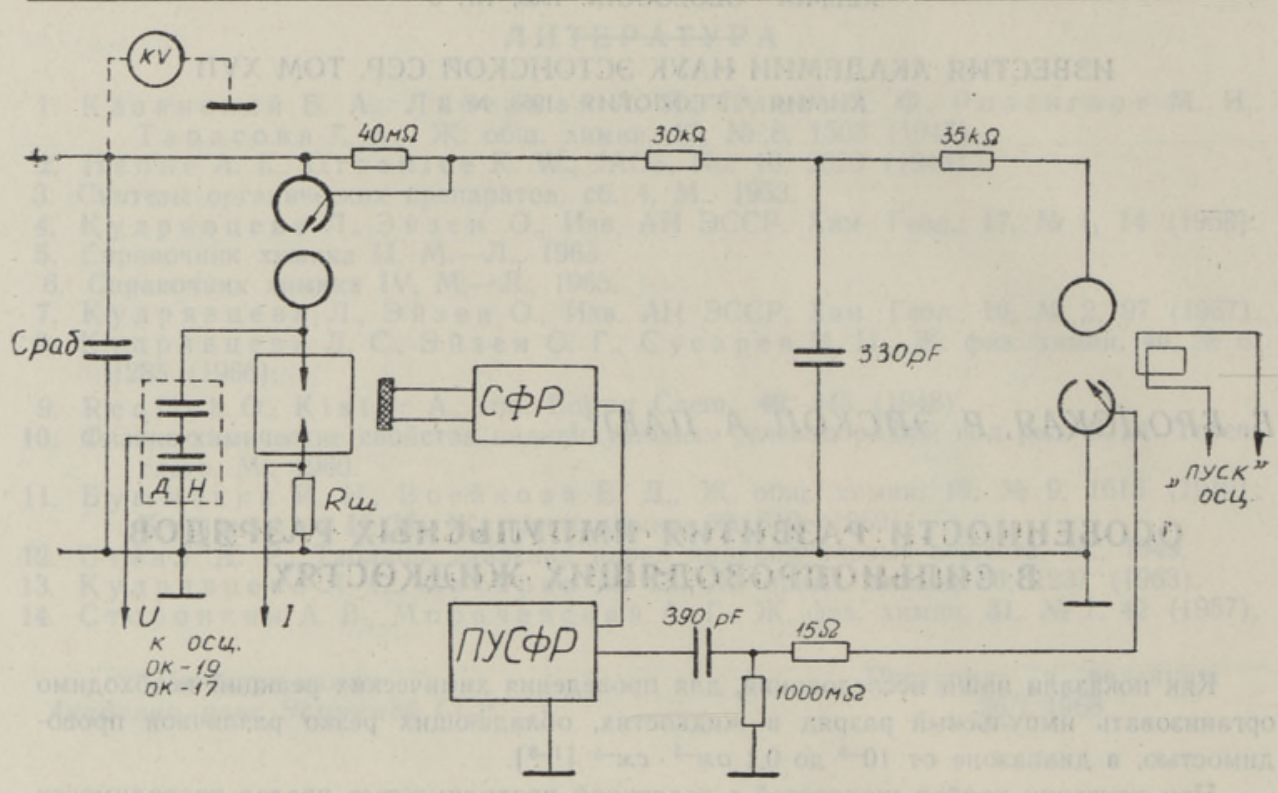

Рис. 1. Принципиальная схема импульсной установки.

пульсом, поступавшим от СФР-2М. Таким образом, синхронно с оптической картиной разряда регистрировались напряжение на разрядном промежутке и ток.

Исследование проводилось в герметичных реакторах: в стальном реакторе цилиндрической формы, позволяющем изменять емкость, и в плексиглазовом реакторе прямоугольной формы, с отверстиями для производства фотоснимков, отбора проб газа и жидкости. Процесс развития разрядов изучался для симметричного искрового промежутка типа острие - острие С-C (точечные электроды) и несимметричного острие плоскость С-П при различных полярностях импульсных напряжений и межэлектродных расстояниях от 3 до 20 м.м.

Разряды исследовались в щелочных (KOH), кислых $\left(\mathrm{H}_{2} \mathrm{SO}_{4}\right.$, раствор Фрике) и нейтральных средах $(\mathrm{NaCl}, \mathrm{KCl})$. Изменение электропроводности достигалось различной концентрацией электролита в растворе. Электропроводность исследуемой жидкости измерялась кондуктометром ММЗЧ-64. Кондуктометрическнй датчик представлял собой сосуд с двумя платиновыми электродами.

В отдельных случаях основные электрические характеристики разряда определялись графо-аналитическим методом, с использованием зависимости и закона сохранения энергии для цепи, состоящей из последовательного соединения $C, L$ и $R\left[{ }^{9}\right]$ :

$$
P_{h}=d \frac{L i^{2}}{2} / d t+d \frac{C u^{2}}{2} / d t .
$$

Результаты такого графического построения позволили разделить зарегистрированное на осциллограмме напряжение $U=f(t)$ на активную $U_{R}=R_{k}(t)$, индуктивную $L_{L}^{\prime}=L_{k}(t) d i / d t$ и емкостную $U_{C}=U_{0}-1 / C \int^{t} i d t$ составляющие и проследить за их изменением в ходе разряда, а также за изменением во времени сопротивления плазменного канала. Для определения изменения удельного сопротивления $\varrho$ и плотности тока $\gamma$ в период образования и расширения плазмы производились также скоростные снимки.

\section{Результаты исследований}

Всего было проведено около тысячи опытов. Параллельные опыты с сильно проводящими электролитами отличались хорошей воспроизводимостью. 
Исследования показали, что в изучаемых электролитах с электропроводностью до $0,1 \mathrm{oM}^{-1} \cdot \mathrm{CM^{-1 }}$ возможно образование плазменного пробоя.

Изменение концентрации электролита приводит, при прочих равных условиях, к изменению характера развития разряда. С уменьшением электропроводности с $10^{-1}$ до $10^{-5} \mathrm{oM}^{-1} \cdot \mathrm{cm}^{-1}$ средняя скорость развития светящихся ионизированных ветвей возрастает от $(0,4-1,2)$ до (2040) $к м / с е к$, а ветвистость уменьшается от $(20-30)$ до $(1-3)$.

Для иллюстрации на рис. 2 и 3 приведены скоростная фотография развития разряда, осциллограммы тока и напряжения в растворе $\mathrm{NaCl}$ при различной проводимости (рис. 2,3 ). Как видно из рисунков, в одном случае образуется мощный плазменный пробой, в другом - густая сеть самосветящихся ветвей, отходящих от электродов. Осциллограммы показали, что следует различать два режима разряда - режим пробоя с периодически затухающим разрядом, с характерным срывом напряжения и скачком тока и режим стекания заряда конденсаторов в среду с характерным плавным спадом напряжения.

Отсутствие пробоя в случае повышенной проводимости электролитов обусловлено несоответствием параметров разрядной цепи.

При увеличении энергии (разрядной емкости) или уменьшении межэлектродного промежутка плазменный пробой происходит и во втором случае, при более высоких значениях проводимости.

В табл. 1 приведены основные показатели развития разрядов в дозиметрическом растворе Фрике $\gamma=0,135$ ом $^{-1} \cdot \mathrm{CM}^{-1}$ при расстояниях между точечными электродами от 3 до 20 мм и энергии единичных импульсов от 45 до 1300 дю.

Приведенные данные являются усредненными по результатам пятивосьми измерений и вычислений.

С увеличением межэлектродного промежутка в бесплазменном режиме длина самосветящихся ветвей почти не изменяется и средняя скорость их прорастания снижается (при прочих равных условиях) незначительно. Таким образом, для образования ионизированных ветвей решающее значение имеет распределение градиентов электростатического поля в приэлектродной области.

Одной из особенностей развития разряда в сильнопроводящих жидкостях является соизмеримость максимальных значений токов при стекании заряда конденсаторов и при пробое, измеряемых килоамперами.

Развитие разряда в концентрированных электролитах $\gamma=0,1$ до $10^{-3}$ ом $^{-1} \cdot c M^{-1}$ сопровождается образованием густой сети самосветящихся ветвей, развивающихся от острия при любой полярности.

Увеличение разрядной емкости при неизменном напряжении приводит к интенсификации .ионизационных процессов, выражающихся в распространении ветвей по силовым линиям электрического тока вглубь разрядного промежутка. Перекрытие межэлектродного пространства происходит в результате преобладающего развития одной или нескольких близко расположенных друг к другу ветвей.

При дальнейшем незначительном увеличении емкости происходит пллазменный пробой.

Процессы электролиза и газовыделения играют значительную роль в развитии разрядов.

О роли ионизационных процессов до образования пробоя свидетельствуют результаты определения выхода окисленного железа в зависимости от мощности дозы, которые близки к данным радиационно-химического окисления [ $\left.{ }^{2}\right]$. 


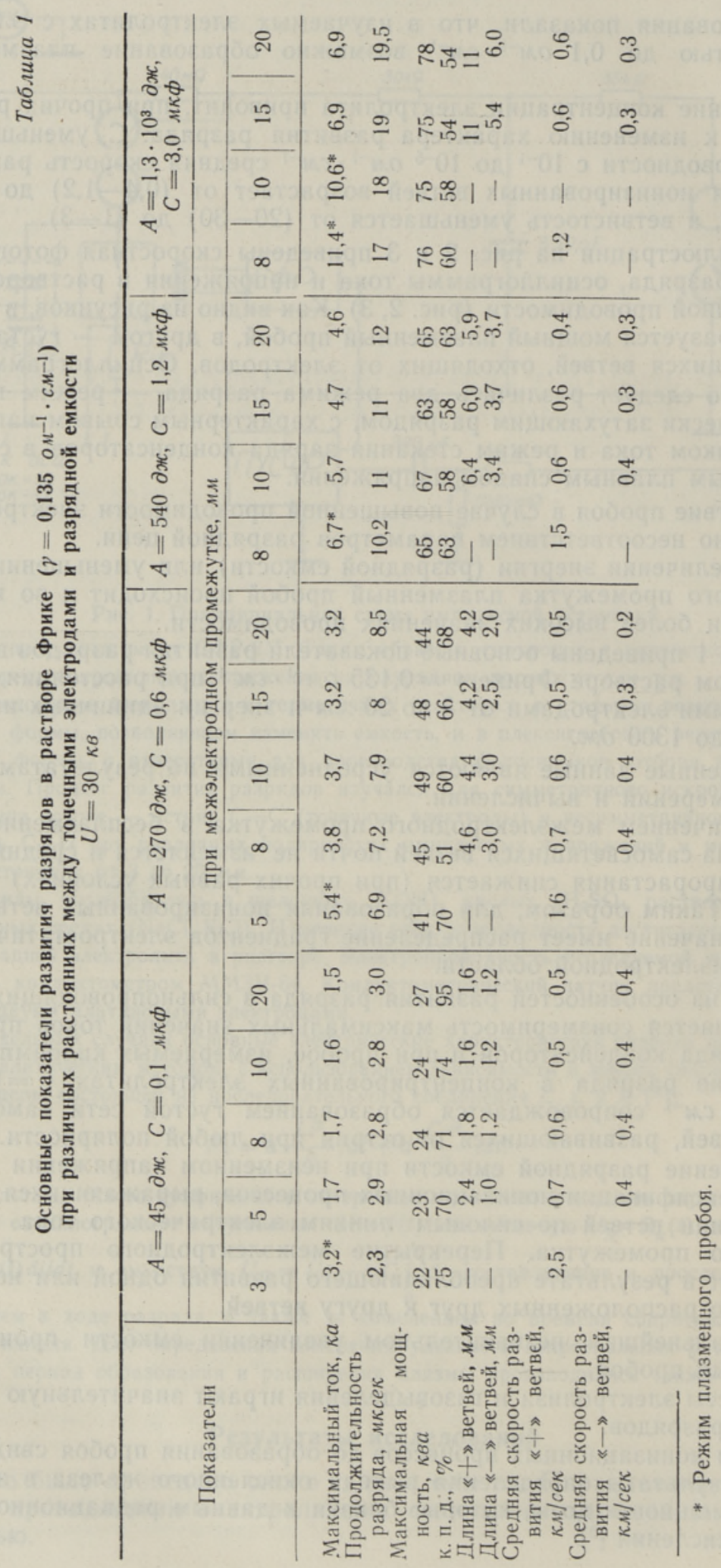


Таблица 2

Основные показатели развития импульсных разрядов в водных растворах при одинаковой электропроводности $L=15 \mathrm{\mu м,} \gamma=0,135 \mathrm{oм}^{-1} \cdot \mathrm{cM}^{-1}, U=30 \kappa 8$

\begin{tabular}{|c|c|c|c|c|c|c|c|c|c|}
\hline \multirow{3}{*}{ Показатели } & \multicolumn{3}{|c|}{$\mathrm{H}_{2} \mathrm{SO}_{4}$} & \multicolumn{3}{|c|}{$\mathrm{KOH}$} & \multicolumn{3}{|c|}{$\mathrm{NaCl}$} \\
\hline & \multicolumn{9}{|c|}{ при емкости, мкф } \\
\hline & 0,6 & 1,2 & 2,4 & 0,6 & 1,2 & 2,4 & 0,6 & 1,2 & 2,4 \\
\hline Максимальный ток, ка & 3,0 & 4,45 & 5,8 & 2,7 & $3, \bar{i}$ & 5,0 & 3,0 & 3,9 & 5,3 \\
\hline $\begin{array}{l}\text { Продолжительность раз- } \\
\text { ряда, мксек }\end{array}$ & 8,8 & 11,2 & 16,2 & 8,75 & 13,7 & 17,5 & 8,7 & 11,2 & 15,0 \\
\hline $\begin{array}{l}\text { Моіноость разряда, квт } \\
\text { К. п. д., \% }\end{array}$ & $\begin{array}{l}63,0 \\
96,4\end{array}$ & $\begin{array}{l}74,0 \\
73,3\end{array}$ & $\begin{array}{l}93,2 \\
65,5\end{array}$ & $\begin{array}{l}64,2 \\
99,4\end{array}$ & $\begin{array}{l}73,0 \\
80,8\end{array}$ & $\begin{array}{l}92,2 \\
72,5\end{array}$ & $\begin{array}{l}55,7 \\
88,0\end{array}$ & $\begin{array}{l}69,0 \\
68,5\end{array}$ & $\begin{array}{l}80,0 \\
66,5\end{array}$ \\
\hline Сопротивленис, ом & 4,0 & 1,5 & 0,12 & 4,0 & 2,3 & 2,2 & 4,0 & 2,0 & 1,0 \\
\hline Энергия, дж & 2603 & 395 & 706 & 268 & 390 & 781 & 260 & 369 & 718 \\
\hline Длина «十» ветвей, мм & 6,3 & 5,6 & 5,0 & 6,3 & 4,5 & 4,3 & 6,3 & 5,6 & 4,3 \\
\hline Длина «一 ветвей, мм & 4,5 & 5,0 & 10 & 3,0 & 4,0 & 5,0 & 3.0 & 3,5 & 5,0 \\
\hline $\begin{array}{l}\text { Скорость развития «†» } \\
\text { ветвей, мк/сcк }\end{array}$ & 2,5 & 3,0 & 5,0 & 2,5 & 3,5 & 4,0 & 2,5 & 3,0 & 4,0 \\
\hline $\begin{array}{l}\text { Скорость развития «一 } \\
\text { ветвей, мк/сек }\end{array}$ & 1,12 & 0,94 & 1,0 & 0,75 & 0,53 & 0,53 & 0,75 & 0,66 & 0,53 \\
\hline $\begin{array}{l}\text { Время до максимального } \\
\text { свечения, мксек }\end{array}$ & 4,0 & 5,3 & 10,0 & 4,0 & 6,6 & 9,35 & 4,0 & 5,32 & 9,35 \\
\hline Время свечения, мксек & 15,3 & 22,0 & 48,6 & 33,3 & 48,0 & 58,6 & 44,6 & 65,3 & 106 \\
\hline
\end{tabular}

При одинаковой высокой электропроводности и вводимой в разрядный промежуток энергии от 50 до 1000 дж наблюдается различие в развитии разрядов в зависимости от рода ионов и их концентрации в водном растворе.

Это можно проиллюстрировать данными о действии разрядов в средах, характеризующихся различной $\mathrm{pH}: \mathrm{H}_{2} \mathrm{SO}_{4}, \mathrm{KOH}$ и $\mathrm{NaCl}$. Электропроводность всех трех растворов равна $0,135 \mathrm{o} \mathfrak{u}^{-1} \cdot \mathrm{cm}^{-1}$. При отсутствии плазменного пробоя осциллограммы тока и напряжения почти одинаковы. Различие отмечается лишь при сопоставлении скоростных фотографий (см. рис. 4).

В начале процесса наблюдается эмиссионное свечение у катода. При дальнейшем развитии ветвей это явление не играет существенной роли.

В кислой среде происходит развитие ветвей преимущественно от положительного электрода. В щелочной и нейтральной средах полярность выражена слабо. Различие отмечается в продолжительности видимого свечения - от максимальной интенсивности до полного затухания. Этот период наибольший у $\mathrm{NaCl}$ и наименьший у $\mathrm{H}_{2} \mathrm{SO}_{4}$. Различие в развитии разряда в зависимости от рода ионов обнаруживается еще больше при увеличении разрядной емкости. На рис. 5 приведены скоростные фотографии тех же растворов электролитов и при энергии, равной 1000 дж.

Как видно из рис. 5 , в растворе $\mathrm{H}_{2} \mathrm{SO}_{4}$ соединение самосветящихся каналов привело к образованию плазменного пробоя. В случае раство-, ров $\mathrm{KOH}$ и $\mathrm{NaCl}$ увеличение энергии до 1000 дж приводило лишь к увеличению объема самосветящейся зоны. Осциллограммы тока и напряжения (см. рис. 6) различны и подтверждают образование плазменного пробоя в растворе $\mathrm{H}_{2} \mathrm{SO}_{4}$ с характерным срывом напряжения и незначительным скачком тока.

Основные показатели развития импульсных разрядов в водных раст- 
ворах при одинаковой электропроводности и различных параметрах разрядной цепи приведены в табл. 2. Эти данные подтверждают, что род ионов влияет на развитие импульсных разрядов.

При развитии разрядов в сильных электролитах, так же как и в других жидкостях, наблюдается эффект полярности $\left[{ }^{4-7}\right]$.

В наших опытах отличительной особенностью является меньшая выраженность этого эффекта и зависимость не только от электропроводности раствора, но и от рода ионов и величины подводимой энергии.

С увеличением электропроводности растворов эффект полярности уменьшается.

При значительном увеличении концентрации электролита решающую роль в развитии каналов играют токи проводимости и меньшую - ионизационные процессы.

Этим, по-видимому, можно объяснить тот факт, что ветви развиваются как от положительных, так и от отрицательных электродов. Образование большого числа ветвей приводит к изменению градиента поля острия, к выравниванию поля и созданию эквивалентных условий для образования светящихся ветвей вдоль любой из силовых линий.

\section{Выводы}

Установлена возможность развития плазменного пробоя в сильных электролитах (кислых, іцелочных и нейтральных средах). Выявлены особенности развития ионизированных ветвей в зависимости от электропроводности и концентрации растворов и от рода ионов.

\section{Л ИТ ЕРА Т Р А}

1. Бродск а я Б., Изв. АН ЭССР, Сер. фнз.-матем. и техн. наук, 15, № 3, 454 (1966).

2. Г у бергриц М., Брод к ая Б., П а а ль е Л., Изв. АН ЭССР, Серия физ.-матем. и техн. наук, 15, № 3, 462 (1966).

3. Бр одск а я Б., П а а ль м е Л., Г у бе р г р и ц М., Развитие электрических разрядов при ведении химических реакций в жидкостях различной проводимости. Тр. конфер. по электрической обработке материалов, 1967 г., АН МССР (в печати).

4. Ба лыгин И. Е., Электрическая прочность жидких диэлектриков, М.-Л., 1964.

5. Пробой диэлектриков и полупроводников, Сб. докл. на IV Межвузовской конференции по пробою диэлектриков и полупроводников, «Энергия», 1964.

6. К у жикин И. П., ЖТФ, 36, вып. 9 (1966).

7. Мельников Н. П., О с т о у мов Г. А., С тояк М. Ю., ЖТФ, 39, вып. 4 (1964).

8. С то як М. Ю., Электронная обработка материалов, № 4, 6 (1966).

9. Андре в С. И., В анюков М. И., ЖТФ, 31, вып. 9, 61 (1965).

$\begin{array}{cc}\text { Ннститут химии } & \text { Поступила в редакцию } \\ \text { Академии наук Әстонской ССР } & 12 / \text { III } 1968\end{array}$

B. BRODSKAJA, R. EISKOP, A. PAJU

\section{IMPULSSLAHENDUSTE ARENEMISE ISEÄRASUSED HEA ELEKTRIJUHTIVUSEGA VEDELIKES}

Körgepinge elektrilahenduste arenemise elektrofüüsikalisel uurimisel erineva elektrijuhtivusega vedelikes saadi piisavaid lähteandmeid tarvilike režiimide loomiseks, mis peavad kindlustama keemiliste reaktsioonide kulgemise happelistes, leeliselistes ja neutraalsetes keskkondades.

Keemiliste reaktsioonide teostumiseks, sōltuvalt nende iseloomust, on vaja organiseerida impulsslahendus vedelikes, mille elektrijuhtivus on diapasoonis $10^{-5}$ kuni $0,1 \Omega^{-1}$ $\mathrm{cm}^{-1}$. 

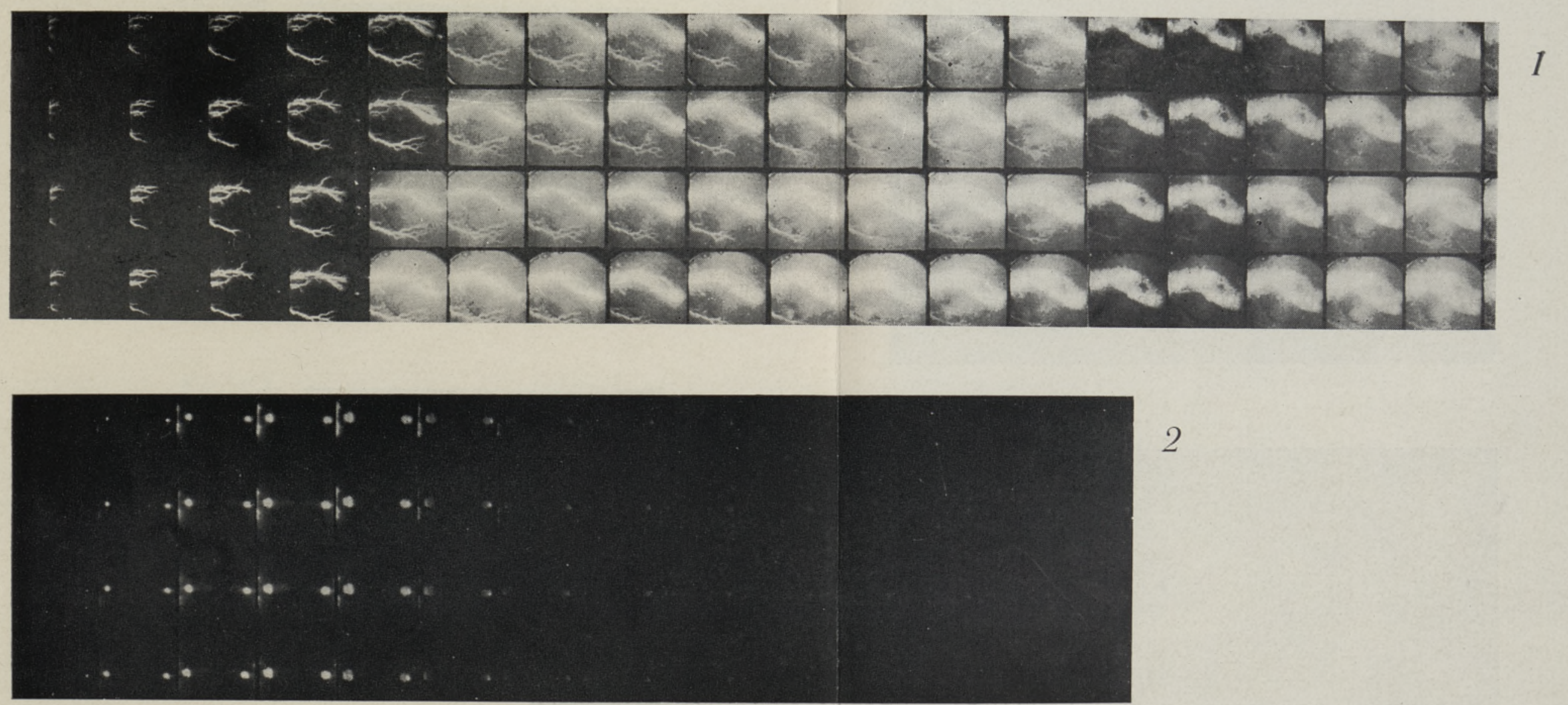

Рис. 2. Скоростная фотография развития разряда $\left(1,5 \cdot 10^{6}\right.$ кадр/сек) в растворе $\mathrm{NaCl}$ при различной проводимости:

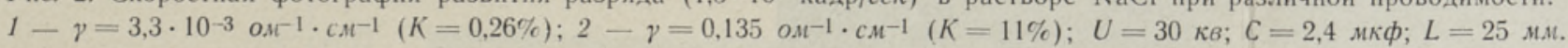

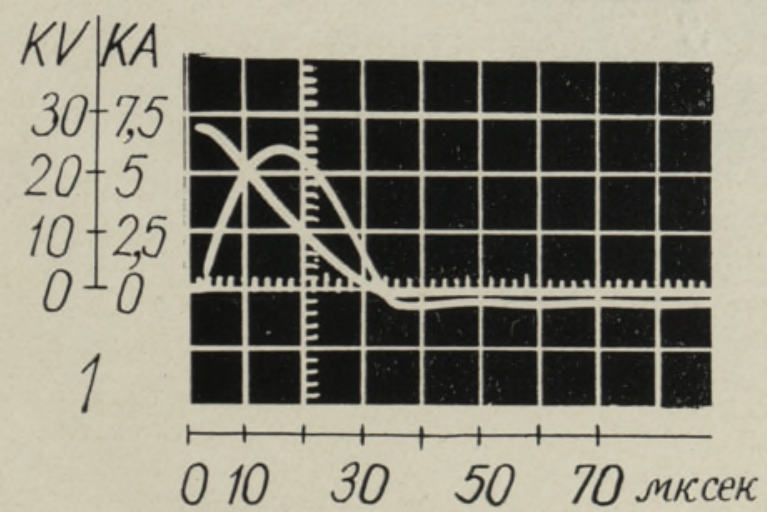

$1-\gamma=3,3 \cdot 10^{-3} \mathrm{om}^{-1} \cdot \mathrm{cm}-1 \quad(K=0,26 \%)$;

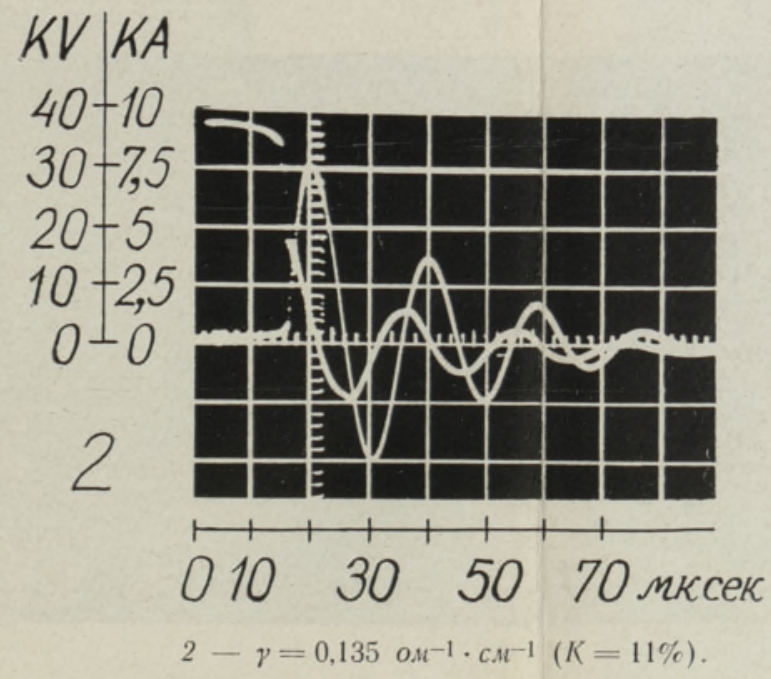

Рис, 3, Осциллограммы тока и напряжения для раствора $\mathrm{NaCl}$ с различной проводимостью $(U=30 \kappa в ; C=$ $=2,4 \quad \mu \kappa \phi, L=25 \mu м)$ : 


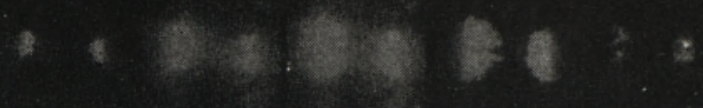

Рис. 4. Скоростная фотография развитня разряда $\left(1,5 \cdot 10^{6}\right.$ кадр/сек) в электролнтах с одннаковой электропроводностью $\gamma=$ $=0,135 o \mu^{-1} \cdot c \mu^{-1}$ и с энергней $A=250 \partial \varkappa$, вводимой в разрядный промежуток:

$$
\begin{aligned}
& 1-\mathrm{H}_{2} \mathrm{SO}_{4} \\
& 2-\mathrm{KOH} \\
& 3-\mathrm{NaCl}
\end{aligned}
$$

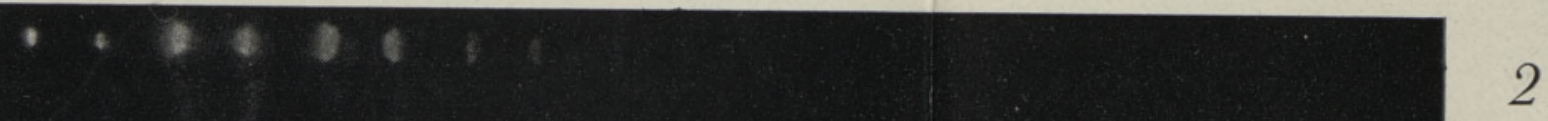

- 0.40

$\div 04 \% 1$

10130

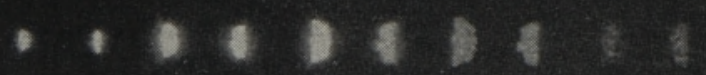

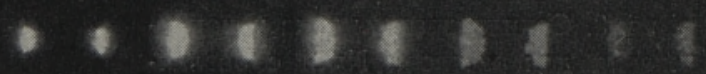

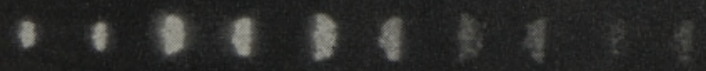




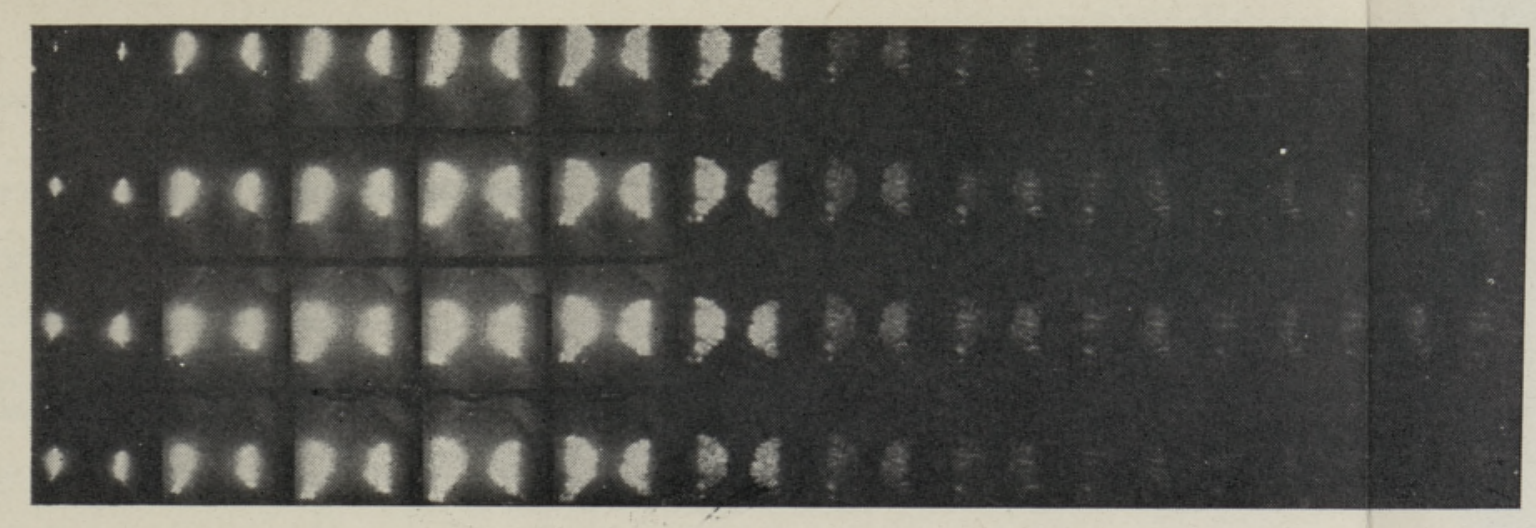

Рис. 5. Скоростная фотография развития разряда $\left(1,5 \cdot 10^{6}\right.$ кадр/сек в электролитах c одинаковой электропроводностью $v=$ $=0,135$ ом-1 $c M^{-1}$ и с энергией $A=$ $=100 \partial \varkappa$, вводимой в разрядный промежуток: $1-\mathrm{NaCl}$; $2-\mathrm{KOH}$; $3-\mathrm{H}_{2} \mathrm{SO}_{4}$.
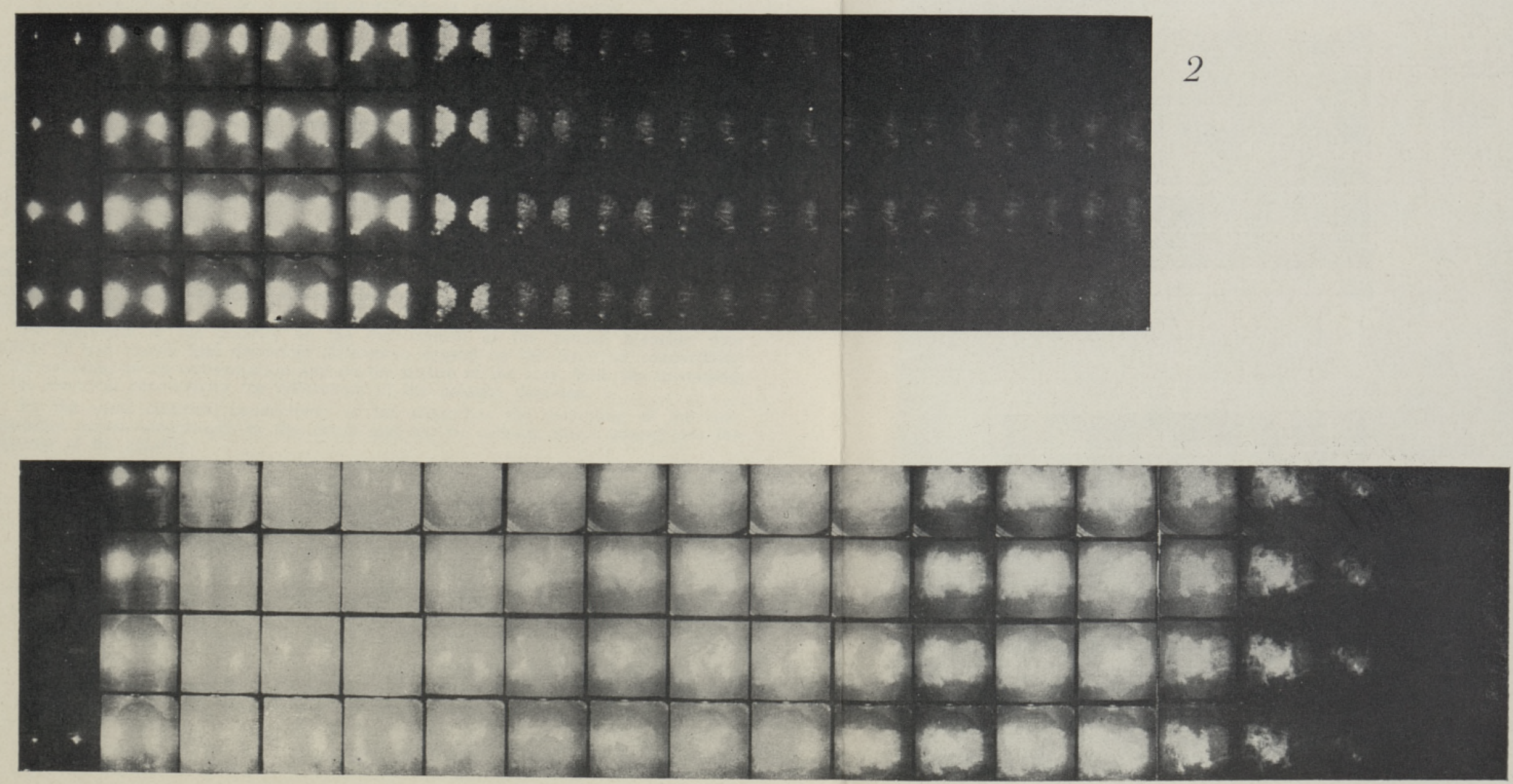


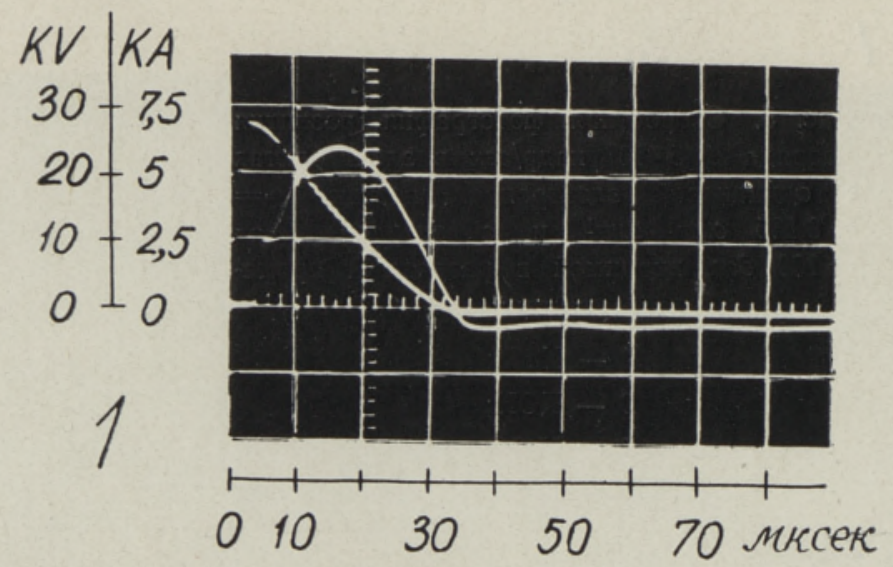

Рнс. 6. Осциллограммы тока и напряжения для растворов с одинаковой электропроводностью $\gamma=0,135 \cdot \mathrm{oM}^{-1} \cdot \mathrm{cM^{-1 }}$ и энергией $A=1000 \partial ж$, вводимой в разрядный промежуток:

$$
\begin{aligned}
& 1-\mathrm{NaCl} ; \\
& 2-\mathrm{KOH} ; \\
& 3-\mathrm{H}_{2} \mathrm{O}_{4}
\end{aligned}
$$
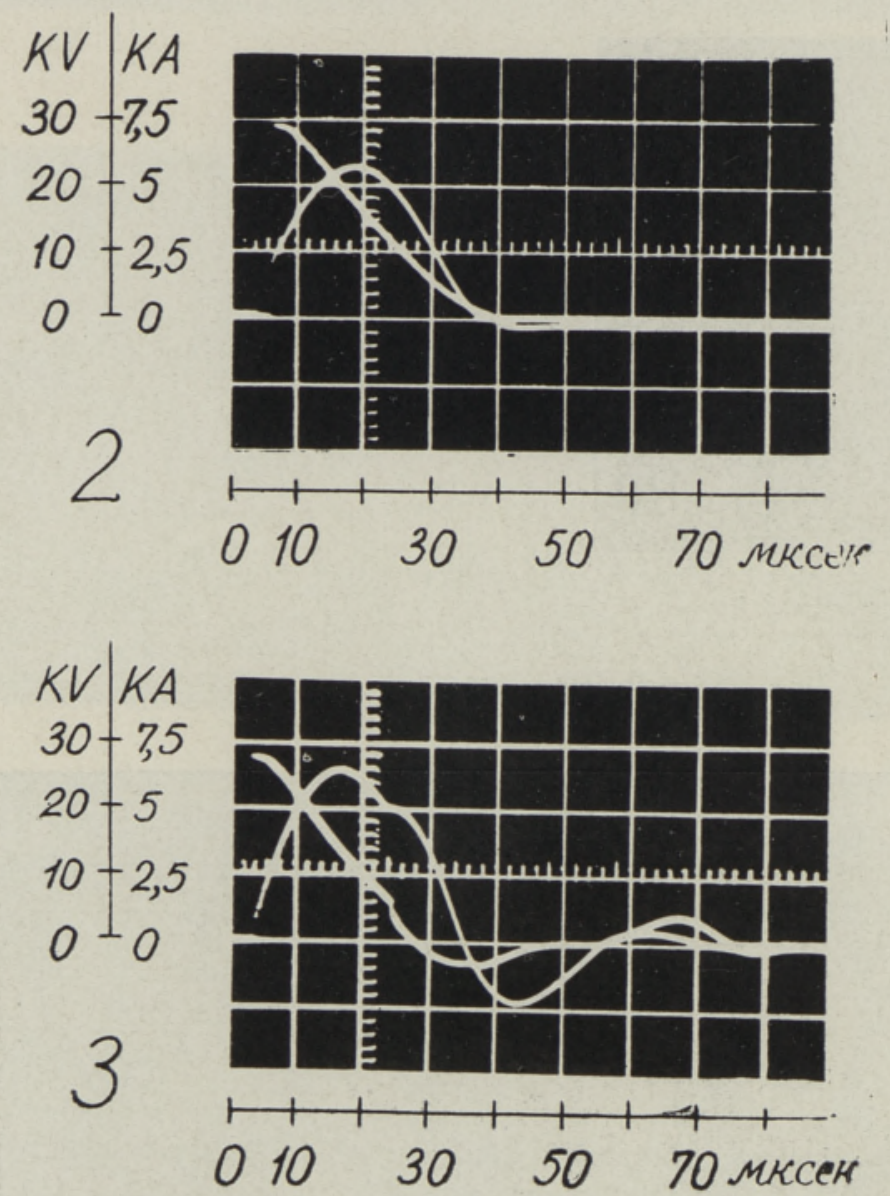
Artiklis on näidatud plasmalise läbilöögi teostatavus hästi juhitavais vedelikes ja ioniseeritud harude arenemise iseärasused.

Optilise uurimise tulemusena tehti ülikiirkaameraga fotografeerides kindlaks, et ühesuguste katsetingimuste korral kasvab elektrijuhtivuse (kontsentratsiooni) vähenemisel isehelenduvate ioniseeritud harude arenemise kiirus, väheneb hargnevus ja kergenevad plasmalise läbilöögi tingimused.

Uuriti polaarsuse mõju ioniseeritud harude arenemisele. Näidati, et numbrilised erinevused sōltuvad lahuse elektrijuhtivusest, tema kontsentratsioonist ja ioonide loomusest. Elektrijuhtivuse tōusuga polaarsuse erinevused vähenevad.

Elektrolüüdi ühesuguse elektrijuhtivuse puhul toimub kontsentratsiooni ümberjaotus vastavalt anoodil ja katoodil, mis veelgi süvendab polaarsuse mõju.

\section{B. BRODSKAYA, R. EISKOP, A. PAJU}

\section{PECULIARITIES OF THE DEVELOPMENT OF PULSE DISCHARGES IN LIQUIDS OF A GOOD ELECTRICAL CONDUCTIVITY}

The result of the investigation of the development of the high voltage electrical discharge in liquids of a different electrical conductivity gave sufficient initial data for the creation of the required regimes which guarantee the proceeding of the chemical reactions in acidic, basic and neutral media.

To carry out chemical reactions depending on their character requires the realisation of the pulse discharge in liquids that have electrical conductivity within the range $10^{-5} \mathrm{ohm}^{-1} \cdot \mathrm{cm}^{-1}$ to $10^{-1} \mathrm{ohm}^{-1} \cdot \mathrm{cm}^{-1}$.

There in the article is shown the realizability of the plasmic break-down in liquids with the good conductivity and the peculiarities of the development of the ionized branches.

It was established by means of optical studies from photographs taken by the fast camera that by the equal conditions of the experiment with the decreasing of the electrical conductivity (concentration) the velocity of the development of the luminous ionized branches increases, the branching decreases and the conditions of the plasmic break-down lighten.

The influence of the polarity on the development of the ionized branches was studied. It was shown that numerical differences depend on the electrical conductivity of the solution, on its concentration and on the nature of the ions. With the increasing of the electrical conductivity the differences of the polarity decrease.

By the equal electrical conductivity of the eletcrolyte the redividing of the concentration occurs accordingly by the anode and by the cathode which strenghtens the influence of the polarity. 